\title{
NFAIS 2012: Introduction
}

How does our information world continue to evolve, where can we expect to find ourselves in the future? The 2012 NFAIS Annual Conference, Born of Disruption: An Emerging New Normal for the Information Landscape, explored these questions in depth. The meeting was held February 26-28, 2012 in the historic Hyatt at the Bellevue, Philadelphia, Pennsylvania, USA. A sampling of the intriguing presentations are included in this issue of Information Services and Use. John Wilbanks began the sessions with a keynote on the emerging information landscape. We ended with an endnote by Joe Esposito projecting the future based on current realities. A special highlight of the meeting was the honorary Miles Conrad Memorial Lecture given by Howard Ratner of Nature Publishing.

In discussing the new landscape attendees heard from Amazon (cloud computing), American Chemical Society (new normal in publishing), Annual Reviews (mobile delivery of content), British Library/JISC (the researcher of the future), California Digital Library (data sets), Columbia University (new normal for libraries), Elsevier (workflow solutions), Gale Cengage (ebooks), Gartner, Inc. (emerging new technologies), Hearst Corp. (semantic web), Mendeley (mashups and API's), Microsoft (digital libraries), Modern Language Association (new normal in the Humanities), Nature Publishing (Miles Conrad Lecture), NIST (Big Data), Pew' Internet \& American Life Project (the normal based upon recent survey results), Public Library of Science (new value metrics), Royal Society of Chemistry (crowd sourcing), Thomson Reuters IP \& Science (global competition), Unlimited Priorities LLC (cloud computing case study), Wolfram Alpha (computational knowledge).

Included below are short summaries of the articles included in this issue to give the reader a taste of the meeting.

Our first article is by Julie Carpenter, Director of Education for Change Ltd. In "Researchers of Tomorrow: The research behavior of Generation Y doctoral students", she reports on the findings of a three-year study commissioned by the British Library and UK Joint Information Systems Committee. An initial premise of the study was that Generation Y students (those born between 1982 and 1994) would have better research skills than Generation X students, skills acquired before a time of over-reliance on internet search for secondary sources. The article indicates the degree of technological sophistication that Gen Y students have, while at the same revealing some of the research methodology weaknesses they share with Gen X students.

In "Moving targets and experiments: One publisher's mobile journey", Jenni Rankin, Marketing Manager at Annual Reviews, recounts a long-established scientific literature review publisher's foray into the world of mobile platforms. In the same vein as the preceding article, she writes, "We're conscious that sociological and technological shifts affect our readership, and that the next-generation's academics are Google-centric multi-taskers". She gives a list of lessons learned, and concludes "To innovate effectively, we need to understand where our readers are now, and where they are going. Our essential task is to solve future problems before our users even realize they have them".

The next article is by Victor Camlek, Vice President for Market Intelligence at Thomson Reuters IP \& Science. In "Measuring global competition", Camlek describes selected leading indicators of global competitiveness. He observes, "The world is becoming increasingly competitive as established economies are joined by emerging economies that are growing at a rapid pace". Emerging economies are 
rapidly achieving top positions in some areas, while smaller countries with established economies are rising in other areas. Camlek notes that "the changes within global competitiveness assessments should have an increasing impact on global trade and commerce, scientific discovery, and overall quality of life, when discovery and scholarship are used for peaceful objectives".

In "Predicting the present", Joseph Esposito, Portable CEO Consulting, discusses four different publishing scenarios for the future. In explanation of his unusual title, he quotes science fiction writer William Gibson: "The future is already here - it's just not evenly distributed". So the article looks at what's already starting to happen in the world of publishing, and explores what those innovations and trends might look like five years from now. A repeating theme is that the future is already here, and Esposito provides numerous examples from the innovators and trendsetters in the publishing world. $\mathrm{He}$ concludes by describing some overarching trends to watch.

Lastly, we have the Miles Conrad lecture presented by Howard Ratner, Chief Technology Officer, Nature Publishing Group. In "Living online", he walks us through a journey that begins with the Watson of IBM quote, "I think there is a world market for about five computers", to the age of "ubiquitous computing" first coined by Mark Weiser. Ratner reflects that his own earlier concept of "Article Particles" that breaks the article down into its component pieces, does not now define what the publishing community should be doing to meet the needs of readers who are consuming and using information in new ways - "Any Time, Anywhere, Any Device".

I look forward to your comments and the next year's meeting!

Marjorie M.K. Hlava President, Access Innovations

Guest Editor 